\title{
Acute kidney injury in SARS-CoV2-related pneumonia ICU patients: a retrospective multicenter study
}

\author{
Guillaume Geri ${ }^{1,2,3,4^{*}+}$ (D), Michael Darmon ${ }^{5,6,7 \dagger}$, Lara Zafrani ${ }^{5,6,8}$, Muriel Fartoukh ${ }^{9,10}$, Guillaume Voiriot ${ }^{9,10,11}$, \\ Julien Le Marec ${ }^{10,12,13}$, Saafa Nemlaghi ${ }^{10,12,13}$, Antoine Vieillard-Baron 1,2,3,4 and Elie Azoulay 5,6,7
}

\begin{abstract}
Background: While acute kidney injury (AKI) is frequent in severe SARS-CoV2-related pneumonia ICU patients, few data are still available about its risk factors.

Methods: Retrospective observational study performed in four university affiliated hospitals in Paris. AKI was defined according to the KIDGO guidelines. Factors associated with AKI were picked up using multivariable mixed-effects logistic regression. Independent risk factors of day 28 mortality were assessed using Cox model.

Results: 379 patients (median age 62 [53,69], 77\% of male) were included. Half of the patients had AKI $(n=195,52 \%)$ including 58 patients (15\%) with AKI stage 1, 44 patients (12\%) with AKI stage 2, and 93 patients (25\% with AKI stage 3). Chronic kidney disease (OR 7.41; 95\% Cl 2.98-18.4), need for invasive mechanical ventilation at day 1 (OR 4.83; 95\% Cl 2.26-10.3), need for vasopressors at day 1 (OR 2.1; 95\% Cl 1.05-4.21) were associated with increased risk of AKI. Day 28 mortality in the cohort was $26.4 \%$ and was higher in patients with AKI (37.4 vs. 14.7\%, $P<0.001)$. Neither AKI (HR $1.35 ; 95 \% \mathrm{Cl} 0.78-2.32$ ) nor AKI stage were associated with mortality (HR [95\% Cl] for stage 1, 2 and 3 when compared to no AKI of, respectively, 1.02 [0.49-2.10], 1.73 [0.81-3.68] and 1.42 [0.78-2.58]).

Conclusion: In this large cohort of SARS-CoV2-related pneumonia patients admitted to the ICU, AKI was frequent, mostly driven by preexisting chronic kidney disease and life sustaining therapies, with unclear adjusted relationship with day 28 outcome.
\end{abstract}

Keywords: Acute kidney injury, COVID-19, Renal replacement therapy

\section{Background}

The outbreak of severe acute respiratory syndrome (SARS-CoV2)-related disease has widely spread for almost a year [1]. The clinical presentation is mainly respiratory, potentially leading to severe respiratory failure [2]. Such a respiratory failure is complex and related to at least several factors including viral direct lung injury as well as multiple microthrombosis [3].

\footnotetext{
*Correspondence: guillaume.geri@aphp.fr

${ }^{\dagger}$ Guillaume Geri and Michael Darmon contributed equally as first authors

${ }^{1}$ Medical Intensive Care Unit, Ambroise Paré Hospital, AP-HP, 9 avenue

Charles de Gaulle, 92100 Boulogne-Billancourt, France

Full list of author information is available at the end of the article
}

Kidney involvement is common in COVID-19 patients and may be observed in up to $40 \%$ of cases [4]. Different histological phenotypes from acute tubular necrosis up to specific glomerular involvement as collapsing glomerulopathy [5-7] have been reported. Pathogenesis of AKI during COVID-19 remains imperfectly understood. Besides cytokine storm, kidney congestion related to right ventricular failure or interactions with mechanical ventilation, endothelitis may be the cornerstone of organ - and especially the kidney-involvement in SARSCoV2-related pneumonia.

\section{Springer Open}

(c) The Author(s) 2021. This article is licensed under a Creative Commons Attribution 4.0 International License, which permits use, sharing, adaptation, distribution and reproduction in any medium or format, as long as you give appropriate credit to the original author(s) and the source, provide a link to the Creative Commons licence, and indicate if changes were made. The images or other third party material in this article are included in the article's Creative Commons licence, unless indicated otherwise in a credit line to the material. If material is not included in the article's Creative Commons licence and your intended use is not permitted by statutory regulation or exceeds the permitted use, you will need to obtain permission directly from the copyright holder. To view a copy of this licence, visit http://creativeco mmons.org/licenses/by/4.0/. 
However, few data are still available about risk factors associated with AKI occurrence and the relationship between inflammatory biomarkers and renal failure.

In the present study, we aimed to evaluate factors associated with AKI occurrence as well as its impact on day 28 mortality in SARS-CoV2 patients admitted to the ICU in four intensive care units from the Parisian area.

\section{Patients and methods Study design, setting and participants}

This retrospective observational study was performed in four university-affiliated hospitals in Paris, as previously reported [8]. Consecutive patients with laboratoryconfirmed SARS-CoV-2 infection admitted to one of the ICUs between 21 February and 24 April 2020 were enrolled. The appropriate ethics committee approved the study and waived the need for informed consent in accordance with French legislation about retrospective studies. Laboratory confirmation of SARS-CoV-2 was defined as a positive real-time reverse transcriptasepolymerase chain reaction (RT-PCR) assay of nasal and pharyngeal swabs [9].

\section{Data collection}

Data were recorded by the intensivists in each ICU. The variables reported in the tables and figures were abstracted from the medical charts and electronic reports. Causes of immunosuppression included solid tumours, haematological malignancies, solid organ transplantation, long-term immunosuppressive therapy (i.e., high-dose steroids ( $>1 \mathrm{mg} / \mathrm{kg}$ whatever the duration) or any immunosuppressant for more than 3 months), and HIV infection [10]. Obesity was defined as previously reported [11]. The SOFA score was calculated within $24 \mathrm{~h}$ of ICU admission [12]. Regards to renal data, day 1 serum creatinine was collected as well as urine output within the first $24 \mathrm{~h}$. To note that some of the patients included from the Saint Louis hospital were already reported elsewhere [13].

\section{Definition of AKI}

AKI was defined according to both urinary output and serum creatinine KDIGO criteria \{KidneyDiseaseImprovingGlobalOutcomesKDIGOAcuteKidneyInjuryWorkGroup:2012gn\} as follows: stage 1-increase in serum creatinine by $0.3 \mathrm{mg} / \mathrm{dl}$ within $48 \mathrm{~h}$ or a 1.5 to 1.9 times increase in serum creatinine from baseline or urinary output $<0.5 \mathrm{ml} / \mathrm{kg} / \mathrm{h}$ for $6-12 \mathrm{~h}$ within 7 days; stage 2-2.9 times increase in serum creatinine or urinary output $<0.5 \mathrm{ml} / \mathrm{kg} / \mathrm{h}$ for $\geq 12 \mathrm{~h}$ within 7 days; stage 3-3 times or more increase in serum creatinine or to $\geq 4.0 \mathrm{mg} /$ $\mathrm{dl}$ or initiation of RRT or urinary output $<0.3 \mathrm{ml} / \mathrm{kg} / \mathrm{h}$ for $\geq 24 \mathrm{~h}$ or anuria for $\geq 12 \mathrm{~h}$ within 7 days. Patients were stratified according to the highest AKI stage attained during the first 7 days of ICU stay.

Baseline creatinine was defined as the best value in the 3 preceding months or if unavailable as the lowest value during ICU stay or was back calculated based on a glomerular filtration rate of $60 \mathrm{~mL} / \mathrm{min} / 1.73 \mathrm{~m} 2$ with MDRD equation in patients without known chronic kidney disease. Chronic kidney disease (CKD) was defined according to the KDIGO definition.

\section{Statistical analysis}

Descriptive statistics were provided as $n(\%)$ and median [interquartile] or mean (standard deviation) for categori$\mathrm{cal}$ and continuous variables, respectively. Comparisons were performed across KDIGO stages of AKI using Pearson Chi-square test and Kruskal-Wallis or ANOVA for categorical and continuous variables, as appropriate.

No imputation for missing data was performed in this analysis and rate of missing data in the overall data set used for this study was $6.8 \%$.

Factors associated with AKI risk were assessed using conditional stepwise regression with 0.2 as the critical $P$ value for entry into the model, and 0.1 as the $P$ value for removal. Interactions and correlations between the explanatory variables were carefully checked. Continuous variables for which log linearity was not confirmed were transformed into categorical variables according to median or IQR. The final models were assessed by calibration, discrimination and relevancy. Residuals were plotted, and the distributions inspected. The final model was planned to be a mixed model taking center effect as random effect on the intercept into account. It was planned to force one by one oxygenation modality, $\mathrm{PaO}_{2} /$ $\mathrm{FiO}_{2}$ ratio, procalcitonin and fibrinogen at ICU admission, in the final model should these variables not be selected.

Independent risk factors of day 28 mortality were assessed using Cox model. Conditional stepwise variable selection was performed with 0.2 as the critical $P$ value for entry into the model, and 0.1 as the $P$ value for removal. It was planned, should this variable not be selected, to force one by one, AKI and AKI severity should these variables not be selected. Interactions and correlations between the explanatory variables were carefully checked. Validity of proportional hazards assumption, influence of outliers, and linearity in relationship between the log hazard and the covariates were carefully checked. Final model was the selected model including frailty effect on center.

Survival curve were plotted using Kaplan Meier curves and influence of AKI on outcome was compared using log-rank test. 
All tests were two-sided, and $P$ values less than 0.05 were considered statistically significant. Analyses were done using $\mathrm{R}$ software version 3.6.2 (https://www.rproject.org), including survival, lme4, lmerTest, givitiR packages.

\section{Results}

\section{Baseline characteristics}

Overall, 379 COVID-19 patients were admitted in the participating ICUs during the study periods (Additional file 1: Figure S1). Main patients' characteristics are described in Table 1. Median age was 62 years [interquartile 53,69] and 291 patients (77\%) were of male gender. Hypertension $(n=188,50 \%)$, diabetes $(n=114,30 \%)$, underlying immune defect $(n=68,18 \%)$ and chronic kidney disease $(n=65,17 \%)$ were the main comorbidities. Two hundred and forty-seven patients were obese $(n=137,39 \%)$ or overweight $(n=110,31 \%)$. Median SOFA score at admission was 5 [3-8]. At ICU admission, half of the patients $(n=204,54 \%)$ required invasive mechanical ventilation, and $165(44 \%)$ vasopressors. Half of the patients had AKI $(n=195,52 \%)$ including 58 patients $(15 \%)$ with AKI stage 1, 44 patients $(12 \%)$ with AKI stage 2, and 93 patients (25\% with AKI stage 3 ).

\section{Factors associated with AKI occurrence}

Main factors associated with AKI before adjustment are reported in Table 1. After adjustment for confounders, chronic kidney disease (OR 7.41; 95\% CI 2.98-18.4), need for invasive mechanical ventilation at day 1 (OR 4.83; 95\% CI 2.26-10.3), need for vasopressors at day 1 (OR 2.1; 95\% CI 1.05-4.21) were associated with increased risk of AKI (Table 2). Conversely, normal troponin level at ICU admission (OR 0.49; 95\% CI 0.25-0.96) and ICU admission more than 7 days after onset of disease (OR 0.40; 95\% CI 0.21-0.76; and OR 0.28; 95\% CI 0.09-0.80, respectively, for patients admitted 8-14 days and more than 14 days after onset of disease) were associated with lower risk of AKI (Table 2). Model calibration is reported in Additional file 1: Figure S2. When forced in the final model, neither $\mathrm{PaO}_{2} / \mathrm{FiO}_{2}$ ratio (OR per $\log 10$ 2.04; 95\% CI 0.47-8.76), procalcitonin at ICU admission (OR per $\mu \mathrm{g} / \mathrm{L} 1.00 ; 95 \%$ CI $0.98-1.02$ ) or fibrinogen level (OR per g/L 1.01; 95\% CI 0.99-1.02) were associated with AKI occurrence. Figure 1 reports adjusted risk of AKI according to initial oxygenation modality.

\section{Relationship between AKI and ICU mortality}

Day 28 mortality in the cohort was $26.4 \%$ and was higher in patients with AKI (37.4 vs. $14.7 \%, P<0.001$, Table 2, Fig. 2). Day 28 mortality in patients with AKI stage 1, 2 , and 3 was of, respectively, $31 \%(n=18 / 58), 34.1 \%$ $(n=15 / 44)$ and $43 \%(n=40 / 93)(p=0.005)$ (Fig. 3 and Additional file 1: Figure S1).

After adjustment for confounders, neither AKI (HR 1.35; 95\% CI 0.78-2.32; Table 3) nor AKI stage were associated with mortality (HR [95\% CI] for stage 1, 2 and 3 when compared to no AKI of, respectively, 1.02 [0.492.10], 1.73 [0.81-3.68] and 1.42 [0.78-2.58]).

As sensitivity analysis, when Chronic Kidney Disease was forced in the final model, this later was not retained (HR 1.48; 95\% CI 0.85-2.58), did not change the final model or influence of AKI on mortality and no interaction between $\mathrm{AKI}$ and $\mathrm{CKD}$ was observed.

\section{Discussion}

In the present study including 379 ICU patients with SARS-CoV2 pneumonia-related acute respiratory failure, AKI occurred in $52 \%$ of cases and was severe in most cases. While chronic kidney diseases and organ failure support were independently associated with AKI occurrence, AKI was not associated with day 28 survival in multivariable analysis.

\section{Incidence of AKI}

AKI is a frequent complication occurring in COVID19 patients. While initial reports indicated that kidney involvement was negligible $[1,14]$, it now appears to account for 20 up to $40 \%$ of patients [15-17] admitted to the hospital. In the present study, we observed a higher incidence of AKI almost due to the fact that we only included patients admitted to the ICU for severe respiratory failure. In an international case series including patients admitted to the ICU, Chaïbi et al. observed similar incidence as 105/211 (49.8\%) patients suffered AKI within the first 7 days after ICU admission; among those, half of them $(n=55)$ had KDIGO3 AKI [18]. This proportion has been evaluated up to $76 \%$ of patients admitted to the ICU in New York City [19].

Besides specific glomerular involvement $[5,6]$ relying to collapsing glomerulopathy related to cytopathogenic effect of SARS-CoV2 on podocytes [20], tubular injury remains the leading cause of AKI in this setting [7]. Such injuries are related to multiple factors as acute right ventricular failure, hypovolemia, proinflammatory cytokines release, endothelial dysfunction, hypercoagulability and mechanical ventilation settings [21].

\section{Factors associated with AKI}

In the present study, we assessed factors associated with AKI occurrence. We observed that life-sustaining therapies as vasopressors and mechanical ventilation as well as preexisting chronic kidney disease were independently associated with AKI. Interestingly, these results did not differ from what we already know in other ICU 
Table 1 Patients characteristics according to occurrence of AKI

\begin{tabular}{|c|c|c|c|}
\hline & No AKI patients & AKI patients & $P$ value \\
\hline$n$ & 184 & 195 & \\
\hline Age (years) & $60[52-68]$ & $63[54-69]$ & 0.03 \\
\hline Male gender & $129(70.1 \%)$ & $162(83.1 \%)$ & 0.004 \\
\hline \multicolumn{4}{|l|}{ Past medical history } \\
\hline Chronic obstructive pulmonary disease & $5(2.7 \%)$ & $15(7.7 \%)$ & 0.05 \\
\hline Asthma & $13(7.1 \%)$ & $10(5.1 \%)$ & 0.57 \\
\hline Hypertension & $72(39.1 \%)$ & $116(59.5 \%)$ & $<0.001$ \\
\hline Diabetes & $44(23.9 \%)$ & 70 (35.9\%) & 0.02 \\
\hline Immune defect & $27(14.7 \%)$ & $41(21.2 \%)$ & 0.13 \\
\hline Chronic heart failure & $8(4.3 \%)$ & $24(12.3 \%)$ & 0.009 \\
\hline Chronic kidney disease & $12(6.5 \%)$ & $53(27.2 \%)$ & $<0.001$ \\
\hline Body mass index, $\mathrm{kg} / \mathrm{m}^{2}$ & $29[26-36]$ & $29[26-32]$ & 0.14 \\
\hline Body weight class & & & 0.63 \\
\hline Overweight & $48(28.9 \%)$ & $62(32.6 \%)$ & \\
\hline Obese & $68(41.0 \%)$ & $69(36.3 \%)$ & \\
\hline Other & $50(30.1 \%)$ & $59(31.1 \%)$ & \\
\hline NSAIDs use before ICU & $5(2.7 \%)$ & $6(3.1 \%)$ & 1.000 \\
\hline Days since onset of disease & & & 0.02 \\
\hline $1-7$ days & $65(35.5 \%)$ & $96(49.7 \%)$ & \\
\hline 8-14 days & $97(53.0 \%)$ & $76(39.4 \%)$ & \\
\hline$>14$ days & $21(11.5 \%)$ & $21(10.9 \%)$ & \\
\hline Days between hospital and ICU admission & $1[0-2]$ & $1[0-3]$ & 0.26 \\
\hline Body Temperature $\left({ }^{\circ} \mathrm{C}\right)$ & $37.6[40.0-38.0]$ & $37.4[36.3-38.3]$ & 0.63 \\
\hline Digestive tract symptoms & $51(27.7 \%)$ & $48(24.6 \%)$ & 0.57 \\
\hline \multicolumn{4}{|l|}{ Laboratory results at ICU admission } \\
\hline Platelets (G/L) & $220[167-284]$ & 199 [146-263] & 0.01 \\
\hline Creatinine $(\mu \mathrm{mol} / \mathrm{L})$ & $69[61-83]$ & $107[78-173]$ & $<0.001$ \\
\hline C Reactive Protein & $159[100-226]$ & $181[106-268]$ & 0.05 \\
\hline Procalcitonin $(\mu \mathrm{g} / \mathrm{L})$ & $0.3[0.2-0.6]$ & $0.8[0.4-1.7]$ & $<0.001$ \\
\hline LDH (UI/L) & $537[454-751]$ & 593 [459-797] & 0.19 \\
\hline Fibrinogene (g/L) & $7.4[6.3-7.5]$ & $7.2[5.8-8.6]$ & 0.10 \\
\hline Ferritin & 1157 [687-2060] & 1554 [856-2749] & 0.09 \\
\hline Ddimeres & $1320[753-2790]$ & 2244 [1025-4003] & 0.001 \\
\hline \multicolumn{4}{|c|}{ Organ support and dysfunction during first $24 \mathrm{~h}$} \\
\hline Oxygenation_modality (\%) & & & $<0.001$ \\
\hline Standard $\mathrm{O} 2$ & $49(26.6 \%)$ & $19(9.7 \%)$ & \\
\hline HFNO/NIV & $74(40.2 \%)$ & $33(16.9 \%)$ & \\
\hline Mechanical_ventilation & $61(33.2 \%)$ & $143(73.3 \%)$ & \\
\hline Normal Troponin & $136(80.5 \%)$ & $70(40.9 \%)$ & $<0.001$ \\
\hline SOFA score & $3[2-5]$ & $7[4-9]$ & $<0.001$ \\
\hline $\mathrm{P} / \mathrm{F}$ ratio $(\mathrm{mmHg})$ & $142[86-191]$ & 124 [90-195] & 0.97 \\
\hline Vasopressors & $42(22.8 \%)$ & $123(63.1 \%)$ & $<0.001$ \\
\hline Need for RRT during ICU stay & $10(5.4 \%)$ & $64(32.8 \%)$ & $<0.001$ \\
\hline Worst KDIGO Stage at day 7 & & & $<0.001$ \\
\hline No AKI & $184(100 \%)$ & $0(0.0)$ & \\
\hline Stage 1 & 0 & $58(29.7 \%)$ & \\
\hline Stage 2 & 0 & $44(22.6 \%)$ & \\
\hline Stage 3 & 0 & $93(47.7 \%)$ & \\
\hline ICU mortality & $30(18.8 \%)$ & $68(42.5 \%)$ & $<0.001$ \\
\hline Hospital Mortality & $30(21.3 \%)$ & $73(57.9 \%)$ & $<0.001$ \\
\hline Day 28 mortality & $27(14.7 \%)$ & $73(37.4 \%)$ & $<0.001$ \\
\hline
\end{tabular}


Table 1 (continued)

Qualitative variables are presented as $n(\%)$ and compared using the Pearson's Chi-square test or the exact Fisher's test, as appropriate

Quantitative variables are presented as median [interquartile] and compared using a Mann-Whitney test

Table 2 Mixed logistic regression assessing risk factors of AKI

\begin{tabular}{llll}
\hline Variable & OR & $\mathbf{9 5 \% ~ C I}$ & P Value \\
\hline Intercept) & 0.49 & $0.11-2.1$ & 0.33 \\
Normal troponin at ICU admission & 0.48 & $0.24-0.96$ & 0.03 \\
Hypertension & 1.70 & $0.92-3.17$ & 0.09 \\
Chronic Kidney Disease & 7.40 & $2.98-18.41$ & $<0.001$ \\
Invasive Mechanical ventilation at day 1 & 4.83 & $2.25-10.33$ & $<0.001$ \\
Vasopressors at day 1 & 2.09 & $1.05-4.20$ & 0.04 \\
Delay since disease onset < 8 days & Ref & - & $\mathrm{NA}$ \\
Delay since disease onset 8 to 14 days & 0.40 & $0.21-0.76$ & 0.005 \\
Delay since disease onset $>$ 14 days & 0.28 & $0.10-0.80$ & 0.02 \\
\hline
\end{tabular}

Center was entered as random effect on the intercept (model calibration see figure $\mathrm{S} 2 ; \mathrm{VIF}<1.5$ for every of the selected variables) patients. This may be an informative illustration of the concept of lung-kidney interaction, relying on the direct consequences of hypoxemia, lack of decarboxylation, inflammatory cytokines release-biotrauma-as well as the direct effect of mechanic ventilation settings on renal perfusion, especially in a context, where acute right ventricular failure is frequent [22,23]. The latter is all the more interesting that we observed that a normal blood troponin level at ICU admission was negatively associated with AKI occurrence. This would reinforce, if we consider an increased troponin level associated with cardiac involvement of SARS-CoV2 infection, the deleterious effect of venous congestion, especially in mechanically ventilated patients. It is to note that we were not

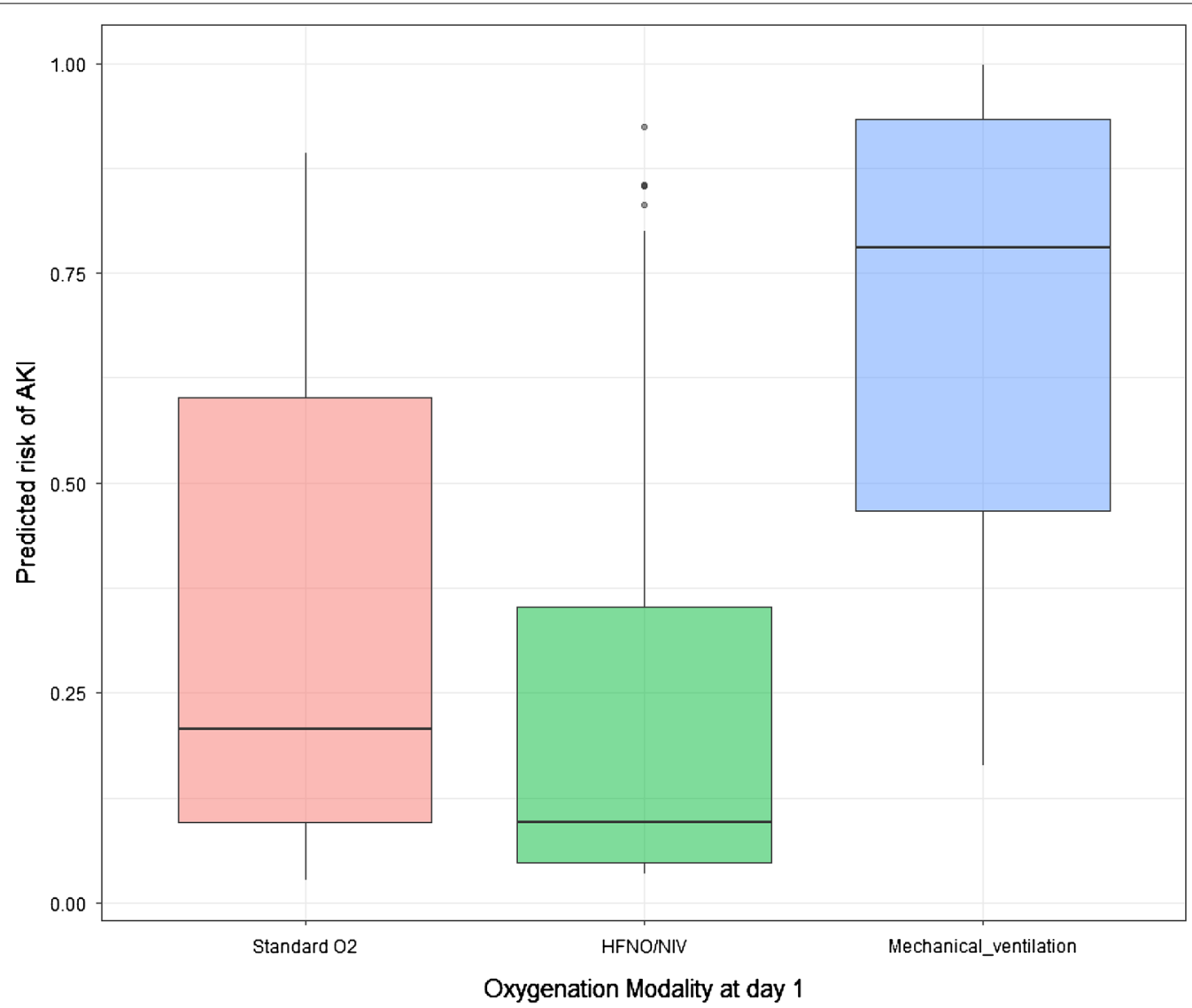

Fig. 1 Predicted probability of acute kidney injury obtained using a multivariable model according to oxygen delivery modality 


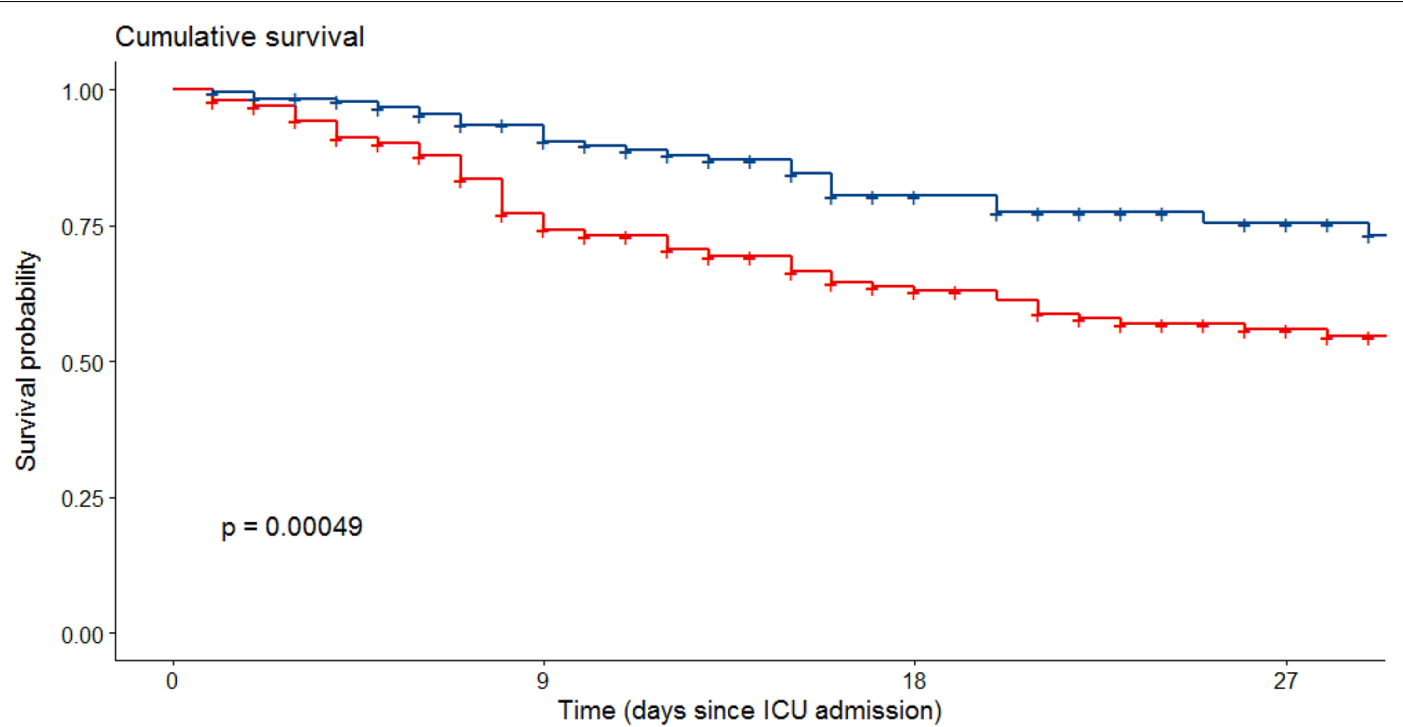

Number at risk

$\begin{array}{lllll}\mathrm{AKl}=0 & 184 & 123 & 54 & 36 \\ \mathrm{AKl}=1 & 195 & 133 & 83 & 48\end{array}$

Fig. 2 Univariate Kaplan-Meier curves according to acute kidney injury

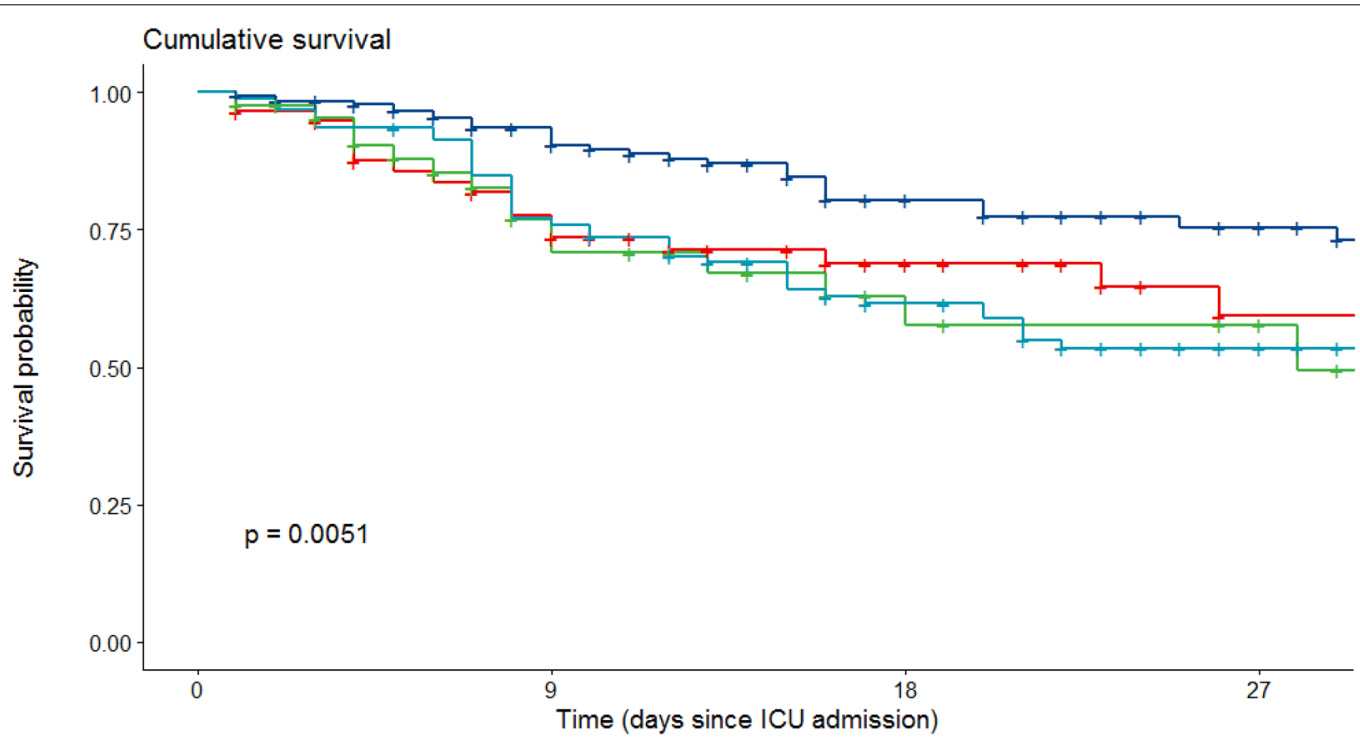

Number at risk

$\begin{array}{ccccc}\text { KDIGOStage }=0 & 184 & 123 & 54 & 36 \\ \text { KDIGOStage }=1 & 58 & 38 & 24 & 10 \\ \text { KDIGOStage }=2 & 44 & 25 & 12 & 8 \\ \text { KDIGOStage }=3 & 93 & 70 & 47 & 30\end{array}$

Fig. 3 Univariate Kaplan-Meier curves according to KDIGO stages of acute kidney injury 
Table 3 Factors associated with day 28 mortality

\begin{tabular}{lccl}
\hline Variable & HR & $\mathbf{9 5 \% ~ C l}$ & P Value \\
\hline Age per year & 1.05 & $1.02-1.07$ & $<0.001$ \\
Normal troponin at ICU admission & 0.42 & $0.25-0.70$ & 0.001 \\
COPD & 2.67 & $1.37-5.22$ & 0.004 \\
Underlying immune defect & 1.97 & $1.22-3.18$ & 0.005 \\
AKI & 1.35 & $0.78-2.32$ & 0.28 \\
Delay since disease onset < 8 days & Ref & - & NA \\
Delay since disease onset 8 to 14 days & 0.51 & $0.35-0.80$ & 0.004 \\
Delay since disease onset > 14 days & 0.39 & $0.15-0.98$ & 0.05 \\
Center effect (frailty) & & & 0.02 \\
\hline
\end{tabular}

Center was entered as frailty effect

able to provide a quantitative relationship between blood level of troponin and AKI that would have reinforced our hypothesis. This is especially related to the multicenter design of the study and the differences in troponin assays used in the different centers. Last, we observed that the longer the delay since disease onset, the lower the probability to suffer from AKI. This might be related to the severity of the respiratory status as we already observed that patients with severe SARS-CoV2 infection admitted within 7 days of disease onset had a higher mortality rate [8].

\section{AKI and outcome in COVID-19 patients}

In the present study, we observed no association between AKI and day 28 outcome. This result is quite discordant with the previously reported ones. Cheng et al. have reported an association between AKI and mortality in a severity-dependent manner [17]. Several other papers reported similar results $[13,19]$. Such a lack of association should raise several hypothesis. First, we should acknowledge we could have missed a real relationship we were not able to observe due to the lack of power of our study. We cannot exclude either that the interaction between AKI and the other life sustaining therapies as vasopressors and mechanical ventilation had precluded us to observe a significant relationship. Second, the onset of AKI should be questioned. Indeed, we observed in the present study the lack of association between AKI at ICU admission and outcome. However, it has been already demonstrated that the relative prognostic weight of AKI was predominant when AKI occurred lately during ICU stay [24]. Hirsch et al. reported two third of patients suffered from AKI after the first $24 \mathrm{~h}$ and the median time of initiation of dialytic support from hospital admission was 2 [interquartile range -2-141] days \{Hirsch:2020ea\}. Moreover, most of patients who required mechanical ventilation and developed AKI had the onset of AKI within $24 \mathrm{~h}$ of intubation. Taken together, this could plead for an underestimation of the prognostic impact of AKI on outcome in our study.

\section{Limitations}

We acknowledge several limitations. First, we cannot draw any causal conclusion regards to the retrospective design of the study. We adjusted for most of the confounders we collected to better appreciate the relationship between patient and ICU factors and AKI occurrence. Second, neither biomarkers nor markers of glomerula (proteinuria and hematuria) or tubular injury were collected. We would probably have measured a much higher incidence of renal involvement in our cohort. Similarly, we did not provide any pro-inflammatory biomarkers as interleukins 1, 6 or 17 . However, we did not observe any independent relationships between daily life inflammation biomarkers and outcome. Third, we did not collect the use of renin-angiotensinaldosteron system inhibitors. We can assume a large proportion of the patients included in the analysis used to take such medications and we cannot rule out a potential relationship AKI occurrence during ICU stay. Fourth, we did not collect longitudinal data about renal function. While this would have been informative, previously reported data have already suggested that AKI occurred mostly within the first $48 \mathrm{~h}$ of ICU stay $[25,26]$. Last, we were not able to evaluate the relationship between mechanical ventilation settings and AKI.

\section{Conclusion}

In this large cohort of SARS-CoV2-related pneumonia patients admitted to the ICU, AKI was frequent, mostly driven by preexisting chronic kidney disease and life sustaining therapies, with unclear adjusted relationship with day 28 outcome.

\section{Abbreviations \\ ICU: Intensive Care Unit; AKI: Acute kidney injury.}

\section{Supplementary Information}

The online version contains supplementary material available at https://doi. org/10.1186/s13613-021-00875-9.

Additional file 1: Figure S1. Flow chart of the study. Figure S2. Calibration of the mixed-effects multivariable model. Calibration plots shows the predicted probability of the outcome calculated from the multivariable model against the events density.

\section{Acknowledgements}

We sincerely acknowledge Alexandre Demoule, Martin Dres and Lola Girodias for their help in collecting the data. 


\section{Authors' contributions}

GG, MD, LZ, MF, GV, JLM, SN, AVB and EA collected the data. GG and MD draw the statistical analysis' plan. MD led the statistical analysis. GG and MD drafted the manuscript. All authors read and approved the final manuscript.

\section{Funding}

None.

\section{Availability of data and materials}

The data sets generated and analysed during the current study are not publicly available.

\section{Declarations}

\section{Ethics approval and consent to participate}

The appropriate ethics committee approved the study and waived the need for informed consent in accordance with French legislation about retrospective studies.

\section{Consent for publication}

Not applicable.

\section{Competing interests}

The authors declare that they have no competing interests.

\section{Author details}

${ }^{1}$ Medical Intensive Care Unit, Ambroise Paré Hospital, AP-HP, 9 avenue Charles de Gaulle, 92100 Boulogne-Billancourt, France. ${ }^{2}$ Paris Saclay University, Gif-sur-Yvette, France. ${ }^{3}$ INSERM UMR 1018, CESP, Villejuif, France. ${ }^{4}$ FHU SEPSIS, Saclay, France. ${ }^{5}$ Medical Intensive Care Unit, Saint Louis Hospital, AP-HP, Paris, France. ${ }^{6}$ Paris University, Paris, France. ${ }^{7}$ INSERM U1153, Centre of Research in Epidemiology and Statistics, Paris, France. ${ }^{8}$ INSERM U976, Immunologie Humaine, Pathophysiologie et immunothérapie, Paris, France. ${ }^{9}$ Medical Intensive Care Unit, Tenon Hospital, AP-HP, Paris, France. ${ }^{10}$ Paris Sorbonne University, Paris, France. ${ }^{11}$ INSERM U955 (IMRB), Equipe GEIC2O, 94000 Créteil, France. ${ }^{12}$ Medical Intensive Care Unit, Pitié-Salpétrière Hospital, AP-HP, Paris, France. ${ }^{13}$ INSERM, UMRS1158 Neurophysiologie Respiratoire Expérimentale et Clinique, Paris, France.

Received: 22 January 2021 Accepted: 13 May 2021 Published online: 31 May 2021

\section{References}

1. Zhu N, Zhang D, Wang W, Li X, Yang B, Song J, et al. A novel coronavirus from patients with pneumonia in China, 2019. N Engl J Med. 2020;382:727-33

2. Guan W-J, Ni Z-Y, Hu Y, Liang W-H, Ou C-Q, He J-X, et al. Clinical characteristics of coronavirus disease 2019 in China. N Engl J Med. 2020;NEJMoa2002032-13.

3. Ackermann M, Verleden SE, Kuehnel M, Haverich A, Welte T, Laenger F, et al. Pulmonary vascular endothelialitis, thrombosis, and angiogenesis in Covid-19. N Engl J Med. 2020;383:120-8.

4. Hirsch JS, Ng JH, Ross DW, Sharma P, Shah HH, Barnett RL, et al. Acute kidney injury in patients hospitalized with COVID-19. Kidney Int. 2020:98:209-18.

5. Kissling S, Rotman S, Gerber C, Halfon M, Lamoth F, Comte D, et al. Collapsing glomerulopathy in a COVID-19 patient. Kidney Int. 2020. https:// doi.org/10.1016/j.kint.2020.04.006

6. Couturier A, Ferlicot S, Chevalier K, Guillet M, Essig M, Jauréguiberry S, et al. Collapsing glomerulopathy in COVID19 patients. Clin Kidney J. 2020

7. Su H, Yang M, Wan C, Yi L-X, Tang F, Zhu H-Y, et al. Renal histopathological analysis of 26 postmortem findings of patients with COVID-19 in China. Kidney Int. 2020;1-9.

8. Azoulay E, Fartoukh M, Darmon M, Geri G, Voiriot G, Dupont T, et al. Increased mortality in patients with severe SARS-CoV-2 infection admitted within seven days of disease onset. 2020; pp. 1-9. https://doi.org/10. 1007/s00134-020-06202-3
9. Alhazzani W, Møller MH, Arabi YM, Loeb M, Gong MN, Fan E, et al. Surviving Sepsis Campaign: guidelines on the management of critically ill adults with Coronavirus Disease 2019 (COVID-19). Intensive Care Med. 2020;1-34.

10. Azoulay E, Mokart D, Kouatchet A, Demoule A, Lemiale V. Acute respiratory failure in immunocompromised adults. Lancet Respir Med. 2019;7:173-86.

11. Kass DA, Duggal P, Cingolani O. Obesity could shift severe COVID-19 disease to younger ages. Lancet. 2020:395:1544-5.

12. Vincent J-L, Moreno R, Takala J, Willatts S, De Mendonça A, Bruining $\mathrm{H}$, et al. The SOFA (Sepsis-related Organ Failure Assessment) score to describe organ dysfunction/failure On behalf of the Working Group on Sepsis-Related Problems of the European Society of Intensive Care Medicine. Intensive Care Med. 1996:22: 707-10.

13. Joseph A, Zafrani L, Mabrouki A, Azoulay E, Darmon M. Acute kidney injury in patients with SARS-CoV-2 infection. Ann Intensive Care. 2020:1-8.

14. Wang D, Hu B, Hu C, Zhu F, Liu X, Zhang J, et al. Clinical characteristics of 138 hospitalized patients with 2019 novel coronavirus-infected pneumonia in Wuhan, China. JAMA. 2020;323:1061-9.

15. Yang X, Yu Y, Xu J, Shu H, Xia J, Liu H, et al. Clinical course and outcomes of critically ill patients with SARS-CoV-2 pneumonia in Wuhan, China: a single-centered, retrospective, observational study. Lancet Respir Med. 2020;8:475-81.

16. Richardson S, Hirsch JS, Narasimhan M, Crawford JM, McGinn T, Davidson $\mathrm{KW}$, et al. Presenting characteristics, comorbidities, and outcomes among 5700 patients hospitalized with COVID-19 in the New York City area. JAMA. 2020;323:2052-8.

17. Cheng $Y$, Luo R, Wang $K$, Zhang M, Wang Z, Dong L, et al. Kidney disease is associated with in-hospital death of patients with COVID-19. Kidney Int. 2020; 1-10.

18. Chaïbi K, Dao M, Pham T, Gumucio-Sanguino VD, Di Paolo FA, Pavot A, et al. Severe Acute Kidney Injury in COVID-19 Patients with Acute Respiratory Distress Syndrome. Am J Respir Crit Care Med. 2020:rccm.202005-1524LE-11.

19. Chan L, Chaudhary K, Saha A, Chauhan K, Vaid A, Zhao S, et al. AKI in Hospitalized Patients with COVID-19. J Am Soc Nephrol. 2020; 382: ASN. 2020050615.

20. Pan X-W, Da Xu, Zhang H, Zhou W, Wang L-H, Cui X-G. Identification of a potential mechanism of acute kidney injury during the COVID-19 outbreak: a study based on single-cell transcriptome analysis. Intensive Care Med. 2020; 1-3.

21. Ronco C, Reis T, Husain-Syed F. Management of acute kidney injury in patients with COVID-19. Lancet Resp Elsevier Ltd. 2020;8:738-42.

22. Joannidis M, Forni LG, Klein SJ, Honoré PM, Kashani K, Ostermann M, et al. Lung-kidney interactions in critically ill patients: consensus report of the Acute Disease Quality Initiative (ADQI) 21 Workgroup. Intensive Care Med. 2019;46:654-72.

23. Evrard B, Goudelin M, Montmagnon N, Fedou A-L, Lafon T, Vignon P. Cardiovascular phenotypes in ventilated patients with COVID-19 acute respiratory distress syndrome. Crit Care. 2020;24:1-5.

24. Guérin C, Girard R, Selli J-M, Perdrix J-P, Ayzac L. Initial versus delayed acute renal failure in the intensive care unit. A multicenter prospective epidemiological study. Rhône-Alpes Area Study Group on Acute Renal Failure. Am J Respir Crit Care Med. 2000;161:872-9.

25 Hoste EAJ, Lameire NH, Vanholder RC, Benoit DD, Decruyenaere JMA, Colardyn FA. Acute renal failure in patients with sepsis in a surgical icu: predictive factors, incidence, comorbidity, and outcome. J Am Soc Nephrol. 2003;14:1022-30.

26. Federspiel CK, Itenov TS, Mehta K, Hsu RK, Bestle MH, Liu KD. Duration of acute kidney injury in critically ill patients. Annals of Intensive Care. New York: Springer International Publishing; 2018; pp. 1-9.

\section{Publisher's Note}

Springer Nature remains neutral with regard to jurisdictional claims in published maps and institutional affiliations. 